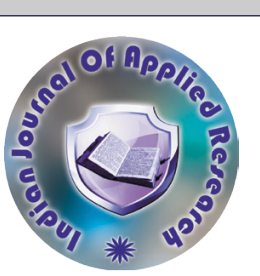

ENT

\title{
A STUDY OF PREVALENCE PATTERN OF MALIGNANCY IN SOLITARY THYROID NODULE AT TERTIARY HEALTH CARE CENTRE
}

\section{Sudheer Kumar Reddy}

B. Nagavardhan Reddy*
BACKGROUND: The common presenting problem like Solitary thyroid nodules (STN) are mostly prevalent in adults. AIMSAND OBJECTIVES: To Study prevalence pattern of malignancy in solitary thyroid nodule at tertiary health care centre. METHODOLOGY: This was a cross-sectional study carried out in the patients of thyroid presenting with solitary thyroid nodule at tertiary health care during the one year period i.e. February 2017 to February 2018. All the patients presented with solitary nodule were after written explained consent were enrolled to study. All details of the patients like age, sex noted. All patients with solitary nodule undergone USG and Histopathological evaluation. The findings were entered in excel sheet and analyzed by Excel for windows 10.

RESULT: In our study the majority of the patients were in the age group of $30-40-29.41 \%, 40-50-25.49 \%, 50-60-21.57 \%,>60-17.65 \%, 20$ $30-5.88 \%$. The majority of the patients were Female i.e. $58.82 \%$, Male were $-41.18 \%$. On USG - Benign lesions were $84.31 \%$, Suspicious were $5.88 \%$, Malignant were $9.80 \%$ on histopathology Benign were $92.16 \%$ and Malignant were $7.84 \%$ As per histopathology the majority of the lesions were Colloid Goitre -29.41\%, Follicular Adenoma-25.49\%, Hashimoto's Thyroiditis- 19.61\%, Hemorrhagic Cyst- 15.69\%, Papillary carcinoma- $3.92 \%$, Follicular carcinoma- $3.92 \%$, MNG- $1.96 \%$.

CONCLUSION: It can be concluded from our study that majority of the patients were in the age group of 30-40, The majority of the patients were FemaleAs per histopathology, majority of the lesions were Colloid Goitre, Follicular Adenoma, Hashimoto's Thyroiditis etc.

\section{INTRODUCTION}

The common presenting problem like Solitary thyroid nodules (STN) are mostly prevalent in adults. Proportions of the patients with thyroid nodules increases along with age ; females have a higher prevalence than males. ${ }^{1}$ Ultra sonography (USG) technique nodules identifies Solitary nodule with successfully and success rate of upto $67 \%, 50 \%$ by autopsy and $8 \%$ by palpation. ${ }^{2,3}$ Palpable types of nodules have been found to reduce in size with disappearance rate of up to $38 \%$. ${ }^{4}$ The main concern associated with thyroid nodules is their chances of malignancy, thyroid cancers are not common and account only $1 \%$ overall cancers and account only $0.5 \%$ of overall deaths associated with cancer. ${ }^{5}$ So, we have seen prevalence pattern of malignancy in solitary thyroid nodule at tertiary health care centre.

\section{METHODOLOGY}

This was a cross-sectional study carried out in the patients of thyroid presenting with solitary thyroid nodule at tertiary health care during the one year period i.e. February 2017 to February 2018. All the patients presented with solitary nodule were after written explained consent were enrolled to study. All details of the patients like age, sex noted. All patients with solitary nodule undergone USG and Histopathological evaluation. The findings were entered in excel sheet and analyzed by Excel for windows 10.

\section{RESULT}

Table 1: Distribution of the patients as per the age

\begin{tabular}{|c|c|c|}
\hline AGE & NUMBER & PERCENTAGE \\
\hline $20-30$ & 3 & 5.88 \\
\hline $30-40$ & 15 & 29.41 \\
\hline $40-50$ & 13 & 25.49 \\
\hline $50-60$ & 11 & 21.57 \\
\hline$>60$ & 9 & 17.65 \\
\hline TOTAL & 51 & 100 \\
\hline
\end{tabular}

The majority of the patients were in the age group of $30-40-29.41 \%$, $40-50-25.49 \%, 50-60-21.57 \%,>60-17.65 \%, 20-30-5.88 \%$.

Table 2: Distribution of the patients as per the sex

\begin{tabular}{|c|c|c|}
\hline SEX & NUMBER & PERCENTAGE \\
\hline MALE & 21 & 41.18 \\
\hline FEMALE & 30 & 58.82 \\
\hline
\end{tabular}

The majority of the patients were Female i.e. $58.82 \%$, Male were $41.18 \%$.
Table 3: Distribution of the various lesions of patients as per the USG and histopathology

\begin{tabular}{|c|c|c|c|}
\hline \multirow{2}{*}{ USG } & No.of Cases & Histopathology Studies & \multirow{2}{*}{ Total } \\
\cline { 2 - 3 } & Benign & Malignant & \\
\hline Benign & 39 & 4 & $43(84.31)$ \\
\hline Suspicious & 3 & 0 & $3(5.88)$ \\
\hline Malignant & 5 & 0 & $5(9.80)$ \\
\hline Total & $47(92.16)$ & $4(7.84)$ & $51(100)$ \\
\hline
\end{tabular}

On USG - Benign lesions were $84.31 \%$, Suspicious were $5.88 \%$, Malignant were $9.80 \%$ on histopathology Benign were $92.16 \%$ and Malignant were $7.84 \%$

Table 4: Distribution of the patients as per the Histopathology

\begin{tabular}{|c|c|c|}
\hline HISTOPATHOLOGY & NO. & PERCENTAGE(\%) \\
\hline Colloid goitre & 15 & 29.41 \\
\hline Follicular adenoma & 13 & 25.49 \\
\hline Hashimotos thyroiditis & 10 & 19.61 \\
\hline Hemorrhagic cyst & 8 & 15.69 \\
\hline Papillary carcinoma & 2 & 3.92 \\
\hline Follicular carcinoma & 2 & 3.92 \\
\hline Multinodular goiter & 1 & 1.96 \\
\hline
\end{tabular}

As per histopathology the majority of the lesions were Colloid Goitre $29.41 \%$, Follicular

Adenoma -25.49\%, Hashimoto's Thyroiditis- $19.61 \%$, Hemo rrhagic Cyst- 15.69\%, Papillary carcinoma- 3.92\%, Follicular carcinoma- $3.92 \% \mathrm{MNG}-1.96 \%$.

\section{DISCUSSION}

Solitary thyroid nodules are defined clinically as a localized thyroid enlargement with an apparently normal adjacent gland. According to literature, STN has a higher risk of malignancy than multiple nodules ${ }^{6}$. Because of this reason, surgeons tend to treat them with high degree of suspicion and plan treatment in a systematic manner.

Clinically, STNs are common, being present in up to $50 \%$ of the elderly population. The majority of STNs are malignant ${ }^{6,12,13}$. Preliminary investigation should include careful history and thorough clinical examination and thyroid function tests. ${ }^{14}$ With the use of imaging techniques, particularly ultrasound, the chance of detection of thyroid nodules has increased many folds. ${ }^{6-11}$ Thyroid cancers occur in approximately $5 \%$ of all thyroid nodules independent of their size ${ }^{8}$.The 
recent data suggest that the incidence of thyroid malignancy is increasing over the years. ${ }^{6.8}$ The occurrence of malignancy is more in solitary thyroid nodules (STN) compared to multinodular goiter ${ }^{6-13}$. The preoperative evaluation of thyroid nodules to distinguish between benign and malignant nodules is very important. It helps to avoid unnecessary extensive surgery and potential surgery related adverse effects, such as hypothyroidism, hypocalcemia, and recurrent laryngeal nerve injury ${ }^{6}$. Thyroid nodule refers to a distinct lesion within the thyroid gland that is palpably or radiologically distinct from the surrounding thyroid parenchyma ${ }^{10}$. Benign causes of thyroid nodule include the colloid nodule and the classical multinodular goiter. Occasionally, nodularity is noticed in patients with Hashimoto's thyroiditis and graves' disease. Malignant causes of nodules include thyroid cancer, lymphoma as well as metastasis to the thyroid gland ${ }^{10}$. Therefore, it is recommended that all thyroid nodules $>1 \mathrm{~cm}$ in size should undergo evaluation. This includes both palpable and nonpalpable nodules, detected by imaging ${ }^{10}$. In our study the majority of the patients were in the age group of $30-40-29.41 \%, 40-50-25.49 \%$, $50-60-21.57 \%,>60-17.65 \%, 20-30-5.88 \%$.

The majority of the patients were Femalei.e. $58.82 \%$, Male were $41.18 \%$. On USG - Benign lesions were $84.31 \%$, Suspicious were $5.88 \%$, Malignant were $9.80 \%$ on histopathology Benign were $92.16 \%$ and Malignant were $7.84 \%$ As per histopathology the majority of the lesions were Colloid Goitre $-29.41 \%$, Follicular Adenoma- $25.49 \%$, Hashimoto's Thyroiditis- $19.61 \%$, Hemorrhagic Cyst- 15.69\%, Papillary carcinoma- $3.92 \%$, Follicular carcinoma- $3.92 \%$, MNG$1.96 \%$. These findings are similar to Rajendran ${ }^{16}$ they found Majority of the patients were between 21-30 years of age. Female:male ratio was about 11.5:1. Swelling in front of the neck was the most common presentation. Most common solitary thyroid swelling was the colloid goitre. Commonest surgery performed was hemithyroidectomy.

\section{CONCLUSION}

It can be concluded from our study that majority of the patients were in the age group of 30-40, The majority of the patients were Female As per histopathology, majority of the lesions were Colloid Goitre, Follicular Adenoma, Hashimoto's Thyroiditis etc.

\section{REFERENCES}

1. Tai JD, Yang JL, Wu SC, Wang BW, Chang CJ. Risk factors for malignancy in patients with solitary thyroid nodules and their impact on the management. J Cancer Res Ther. with solitary thy
$2012 ; 8: 379-83$

2. Wiest PW, Hartshorne MF, Inskip PD, et al. Thyroid palpation versus high-resolution thyroid ultrasonography in the detection of nodules. J Ultrasound Med. 1998; 17: 487-496

3. Cronan JJ. Thyroid nodules: is it time to turn off the US machines? Radiology. 2008; 247: 602-604

4. Usha Menon V, Sundaram KR, Unnikrishnan AG, Jayakumar RV, Nair V, Kumar H. High prevalence of undetected thyroid disorders in an iodine sufficient adult south Indian population. J Indian Med Assoc. 2009; 107: 72-7.

5. Yeung MJ, Serpell JW. Management of the solitary thyroid nodule. Oncologist. 2008; 13:105-12

6. Tai JD, Yang JL, Wu SC, Wang BW, Chang CJ. Risk factors for malignancy in patients with solitary thyroid nodules and their impact on the management. J Cancer Res Ther. 2012; 8: 379-83.

7. Hegedüs L. Clinical practice. The thyroid nodule. NEngl J Med. 2004; 351: 1764-71

8. Yeung MJ, Serpell JW. Management of the solitary thyroid nodule. Oncologist. 2008; 13: 105-12.

9. Usha Menon V, Sundaram KR, Unnikrishnan AG, Jayakumar RV, Nair V, Kumar H. High prevalence of undetected thyroid disorders in an iodine sufficient adult south Indian population. J Indian Med Assoc. 2009; 107:72-7.

10. Unnikrishnan AG, Kalra S, Baruah M, Nair G, Nair V, Bantwal G, et al. Endocrine Society of India management guidelines for patients with thyroid nodules: A position statement. Indian J Endocrinol Metab. 2011;15:2-8.

11. Davies L, Welch HG. Increasing incidence of thyroid cancer in the United States, 19732002. JAMA. 2006; 295:2164-7.

12. Gupta M, Gupta S, Gupta VB. Correlation of fine needle aspiration cytology with histopathology in the diagnosis of solitary thyroid nodule. J Thyroid Res. 2010;2010: 379051.

13. Iqbal M, Mehmood Z, Rasul S, Inamullah H, Shah SS, Bokhari I. Carcinoma thyroid in multi and uninodular goiter. JColl Physicians Surg Pak. 2010;20:310-2.

14. Delbridge L. Solitary thyroid nodule: Current management. ANZ J Surg. 2006; 76; Delbridge L. Solitary thyroid nodule. Current management. ANZ J Surg. 2006; 76 :
381-6.

15. S. Rajendran, K. R. Manoj Prabu. Clinico pathological aspects of solitary thyroid nodule: a hospital based prospective study. Int Surg J. 2018 May;5(5):1852-1855. 